\title{
HUBUNGAN PEMANFAATAN DANA BANTAUAN OPERASIONAL KESEHATAN DENGAN CAKUPAN PROGRAM KESEHATAN IBU DI KABUPATEN KONAWE SELATAN
}

\author{
THE RELATIONSHIP BETWEEN THE UTILIZATION OF HEALTH \\ OPERATIONAL ASSISTANCE FUNDS AND THE COVERAGE OF MATERNAL \\ HEALTH PROGRAMS IN SOUTH KONAWE REGENCY \\ Sija Tiku ${ }^{1}$, Timbul Supodo ${ }^{2}$, Sunarsih ${ }^{2}$ \\ Email: sijahatiku@gmail.com
}

\section{Riwayat Artikel}

Diajukan: Agustus 2019

Diterima: Maret 2020

\section{Penulis Korespondensi:}

- Sija Tiku

- sijahatiku@gmail.com

\section{Kata Kunci:}

Alokasi Dana BOK, Cakupan Program

Kesehatan Ibu, Mini Lokakarya Puskesmas

\begin{abstract}
ABSTRAK
Pendahuluan: Bantuan Operasional Kesehatan (BOK) merupakan program Pemerintah untuk membiayai upaya kesehatan wajib yang mencakup upaya kesehatan promotif dan preventif. Namun hingga saat ini program-program kesehatan yang didanai dari BOK terutama program kesehatan Ibu tidak menunjukkan hasil yang maksimal atau tidak mencapai target Standar Pelayanan Minimal yang diharuskan mencapai target $100 \%$. Setiap tahun kematian Ibu semakin meningkat, cakupan program kesehatan Ibu menurun.
\end{abstract}

Tujuan: Maksud dari penelitian ini bertujuan untuk mengetahui hubungan pemanfaatan dana Bantuan Operasional Kesehatan dengan Cakupan Program Kesehatan Ibu yakni Pelayanan Kesehatan Antenatal ke Empat (K4), Pertolongan Persalinan oleh Tenaga Kesehatan dan Persalinan di Fasilitas Kesehatan di Kabupaten Konawe Selatan dari segi Alokasi Dana BOK dan Pelaksanaan Mini Lokakarya Puskesmas.

Metode: Penelitian ini menggunakan cross sectional study.Populasi dalam penelitian ini adalah Kepala Puskesmas,pengelola dana BOK,pengelola program kesehatan ibu, bidan koordinator dan bidan desa di 23 Puskesmas di Kabupaten Konawe Selatan. Jumlah populasi dalam penelitian ini sebanyak 115 responden.Sampel dalam penelitian ini sebanyak 85 responden dari 17 Puskesmas.Teknik pengambilan sampel dalam penelitian ini menggunakan Stratified Proporsional Simple Random Sampling.Data dianalisis secara deskriptif dan inferensial dilakukan dengan analisis bivariat melalui tahapan chi square.

Hasil: Mayoritas responden usia 26-30, tingkat pendidikan pada strata Diploma III, Hasil penelitian menunjukkan bahwa tidak terdapat hubungan antara Mini Lokakarya Puskesmas dengan cakupan program kesehatan Ibu, dimana diperoleh nilai $\mathrm{X}^{2}$ hitung $<\mathrm{X}^{2}$ tabel $(0,360<3,841)$. Terdapat hubungan bermakna Alokasi Dana BOK dengan Cakupan Program Kesehatan Ibu, dimana nilai $\mathrm{X}^{2}$ hitung $>\mathrm{X}^{2}$ tabel $(4,663>3,841)$ Hasil uji keeratan hubungan menunjukkan koefisien $\operatorname{Phi}(\Phi)$ sebesar 0,427 , hal ini menunjukkan kekuatan hubungan antara Alokasi Dana BOK dengan cakupan program kesehatan Ibu di Kabupaten Konawe Selatan

Kesimpulan: Untuk meningkatkan cakupan program kesehatan Ibu perlu ada evaluasi penggunaan dana BOK di Puskesmas terutama pada 
pembagian Alokasi Dana untuk Kegiatan Program Prioritas dan evaluasi pelaksanaan Mini Lokakarya Puskesmas

Kata Kunci : Alokasi Dana BOK, Cakupan Program Kesehatan Ibu, Mini Lokakarya Puskesmas

\section{ABSTRACT}

Introduction: Health Operational Assistance (HOA) is the government program for financing the mandatory health effort which is include promotive and preventive health effort. However untill now the health programs that funded by BOK (HOA) especially maternal health program is not indicate the maksimum result or it is not achieve the target of Minimum Service Standdard that required to achieve the $100 \%$ targets. Every year the maternal mortality is excelsior, the coverage maternal health is decline.

Objective: This research is aimed to find out the relationship between the utilization of health opperational assistance funds and the coverage of the maternal health program namely the fourth antenatal health service (K4), Childbirth assistance by the health and childbirth labour in health facility in South Konawe regency based on HOA (BOK) fund allocations aspect and the implementation of mini clinic workshop.

Method: The kind of research is cross sectional study. Population in this research are the head of clinic, the HOA (BOK) fund's organizer, the maternal health program's organizer, coordinator midwife, the village's midwife in 23 clinics in South Konawe regency. The population number in this research are 115 respondents. Sample in this research are 85 respondents from 17 clinics. Sample interpretation techniques in this research used Stratified Proportional Simple Random Sampling. Analysis data based on descriptive and inferential held with bivariate analysis by meas of chi square stage.

Result: Majority the respondent's age around 26-30, educational level on stratum Diploma III. The research result indicates that there is no relationship between mini clinic workshop and coverage maternal health program, acquired value $X^{2}$ arithmetic $<X^{2}$ table $(0,360<3,841)$. Existing meaningful relation between BOK (HOA) fund's allocation and coverage maternal health program, value $X^{2}$ arithmetic $<X^{2}$ table $(4,663>$ $3,841)$. The result of closeness relation test indicates coefficient $P h i(\Phi)$ as big as 0,427 , this case indicates the strength relation between BOK (HOA) fund's allocation and coverage maternal health program in South Konawe regency.

Conclusion: interm rise the coverage maternal health program, the evaluatio of BOK (HOA) fund's utilizing is necessary in clinic especially on fund's allocation distribution for priority and evaluation of mini clinic workshop implementation.

Keywords :BOK (HOA) fund allocations, Coverage maternal health program, Mini clinic workshop.

\section{PENDAHULUAN}

Bantuan Operasional Kesehatan (BOK) adalah bantuan pemeritah pusat untuk pemerintah daerah untuk mendukung operasional puskesmas melalui kegiatan kegiatan promotif dan preventif sesuai dengan Peraturan menteri kesehatan no.1 Tahun 2014 (KESEHATAN, 2013). BOK diharapkan dapat meningkatkan derajat kesehatan terutama pada program pelayanan kesehatan Ibu(Aridewi et al., 2013)dengan harapan agar pelayanan kesehatan Ibu yang efektif dapat mengurangi kasus Kematian Ibu (Kemenkes-, 2015).
Pemerintah daerah dan pemerintah pusat terus melakukan berbagai upaya guna memperbaiki dan meningkatkan fasilitas pelayanan kesehatan yang dimulai dari tingkat fasilitas pertama (Jayadipraja et al., 2018). Dukungan pemerintah akan bertambah lagi dengan adanya Bantuan Operasional Kesehatan untuk Puskesmas sebagai salah satu kegiatan inovatif (Kemenkes, 2011). Tahun 2018 dana BOK termasuk dalam Dana Alokasi Khusus (DAK) non fisik (Kemenkes, 2017).

Pemerintah menggunakan Standar Pelayanan Minimal (SPM) bidang kesehatan. SPM adalah hal minimal yang 
harus dilaksanakan oleh Pemerintah daerah untuk rakyatnya, maka target SPM harus $100 \%$ setiap tahunnya. (Hutagalung, 2013)Sehingga dalam menetapkan indikator SPM, Kementerian atau Lembaga Pemerintahan Non Kementerian di Indonesia melakukan pentahapan pada jenis pelayanan, mutu pelayanan atau sasaran serta lokus tertentu (Kemenkes, 2016).Upaya percepatan penurunan AKI dapat dilakukan dengan menjamin agar setiap Ibu mampu mengakses pelayanan kesehatan Ibu yang berkualitas,(Saputra et al., 2013) seperti pelayanan kesehatan Ibu hamil, pertolongan persalinan oleh tenaga kesehatan terlatih di fasilitas pelayanan kesehatan.(Kemenkes, 2018).

Bantuan Operasional Puskesmas (BOK) pemanfaatannya belum sepenuhnya di gunakan untuk kegiatan promotif dan preventif terutama dalam pelayanan kesehatan Ibu,(Hutagalung, 2013)sehingga mengakibatkan terjadinya penurunan cakupan program kesehatan Ibu di Provinsi Sulawesi Tenggara, Pembiayaan yang tidak tepat sasaran, pembagian alokasi dana yang tidak sesuai prioritas masalah, pelaksanaan mini lokakarya puskesmas yang kurang efektif (Dinkes_Prov_Sultra, 2018). Dari 17 (tujuh belas) Kabupaten yang ada di Sulawesi Tenggara, salah satu kabupaten penyumbang Kematian Ibu tertinggi adalah Kabupaten Konawe Selatan hal ini nampak pula pada cakupan program kesehatan Ibu setiap tahunnya mengalami penurunan (Dinkes.Kab..Konsel, 2017).

Jika keadaan ini dibandingkan dengan pembiayaan kesehatan kususnya dana BOK di Kabupaten Konawe Selatan setiap tahunnya mengalami peningkatan. Tahun 2015 sebanyak Rp. 4.161.533.000, Tahun 2016 Rp. 5.911.000.000 dan Tahun 2017 mencapai Rp. 11.559 .609 .000
(Dinkes.Kab..Konsel, 2017), hal ini tidak sejalan dengan capaian cakupan pelayanan kesehatan ibu justru semakin tahun menunjukkan penurunan dan kematian Ibu setiap tahun meningkat. Dari uraian diatas diperoleh permasalahan bahwa cakupan pelayanan kesehatan Ibu tidak sejalan dengan peningkatan jumlah dana BOK. Oleh sebab itu, peneliti tertarik untuk mengkaji "pemanfataan dana BOK di Puskesmas dengan Cakupan Program Kesehatan Ibu (K4, Persalinan oleh tenaga kesehatan dan Persalinan di fasilitas kesehatan) dari segi pelaksanaan Mini Lokakarya Puskesmas dan Alokasi Dana Bantuan Operasional Kesehatan di Kabupaten Konawe Selatan".

\section{METODE}

\section{Desain Penelitian}

Pada penelitian ini jenis penelitian yang digunakan adalah kuantitatif observasional, dengan menggunakan rancangan cross sectional study, dilakukan terhadap 85 responden pada 17 puskesmas pada bulan Mei-Juli 2019 di Kabupaten Konawe Selatan.

\section{HASIL DAN PEMBAHASAN HASIL}

Ditulis dengan jelas menggunakan huruf Hasil penelitian ini menggambarkan hubungan pemanfaatan dana BOK Puskesmas dengan Cakupan Program Kesehatan Ibu yaitu Pelayanan Kesehatan Antenatal ke empat (K4), Persalinan oleh Tenaga Kesehatan dan Persalinan di Fasilitas kesehatan dari segi Pelaksanaan Mini Lokakarya Puskesmas pada Tabel 1, 2 \& 3 dan Pengalokasian Dana BOK serta pada Tabel 4,5 dan 6 
Hubungan Mini Lokakarya Puskesmas dengan Cakupan Program Kesehatan Ibu (Pelayanan Antenatal ke empat (K4), Persalinan oleh Tenaga Kesehatan dan Persalinan di Fasilitas Kesehatan)

Berdasarkan tabel 1, terdapat 27 responden dari 17 Puskesmas menyatakan bahwa Mini Lokakarya Puskesmas terdahap program pelayanan Kesehatan Ibu (K4) kurang, $18(66,7 \%)$ responden cakupannya kurang dan 9 (33,3\%) responden menyatakan cakupan cukup. Dan dari 58 responden di 17 puskesmas menyatakan Mini Lokakarya Puskesmas terdahap program pelayanan Kesehatan Ibu (K4) cukup, terdapat $29(50,0 \%)$ responden yang menyatakan cakupan program Kesehatan Ibu (K4) kurang dan 29 (50,0\%) responden menyatakan cakupan program kesehatan Ibu (K4) cukup. Dari hasil uji statistik dengan menggunakan uji $C h i$ Squarepada $\alpha=5 \%$ dan $\mathrm{df}=1$, diperoleh nilai $X^{2}$ hitung $<X^{2}$ tabel $(1,451>$ 3,841 ), artinya tidak ada hubungan yang bermakna antara Mini Lokakarya Puskesmas dengan cakupan program kesehatan Ibu (K4) di Kabupaten Konawe Selatan. Karena tidak terdapat hubungan maka tidak dilanjutkan dengan uji keeratan hubungan.

Berdasarkan tabel 2, terdapat 27 responden dari 17 Puskesmas menyatakan bahwa Mini Lokakarya Puskesmas kurang terhadap cakupan persalinan oleh tenaga kesehatan, terdapat $14(51,9 \%)$ responden menyatakan cakupan kurang, dan 13 $(48,1 \%)$ menyatakan cakupan Persalinan oleh tenaga kesehatan cukup. Kemudian 58 responden di 17 puskesmas bahwa Mini Lokakarya Puskesmas Cukup terhadapat cakupan persalinan oleh tenaga kesehatan, terdapat $22(37,9 \%)$ responden menyatakan cakupan persalinan oleh tenaga kesehatan kurang dan $36 \quad(62,1 \%)$ responden menyatakan cakupan persalinan oleh tenaga kesehatan cukup. Dari hasil uji statistik dengan menggunakan uji Chi Squarepada $\alpha=5 \%$ dan $\mathrm{df}=1$, diperoleh nilai $X^{2}$ hitung $<X^{2}$ tabel $(0,948>$ 3,841 ), artinya tidak ada hubungan yang bermakna mini lokakarya dengan cakupan program kesehatan Ibu pada Persalinan oleh Tenaga Kesehatan di Kabupaten Konawe Selatan. Karena tidak terdapat hubungan maka tidak dilanjutkan dengan uji keeratan hubungan.

Berdasarkan tabel 3, terdapat 27 responden dari 17 Puskesmas menyatakan bahwa Mini Lokakarya Puskesmas kurang terhadap cakupan persalinan di fasilitas kesehatan, $14 \quad(51,9 \%)$ responden menyatakan cakupan kurang, dan 13 $(48,1 \%)$ responden menyatakan cakupan persalinan di Fasilitas kesehatan cukup. Kemudian dari 58 responden di 17 puskesmas menyatakaan bahwa Mini Lokakarya Puskesmas Cukup terhadap persalinan di Fasilitas Kesehatan (Pf), 22 $(37,9 \%)$ responden menyatakan cakupan persalinan di fasilitas kesehatan kurang dan $36(62,1 \%)$ responden cakupan persalinan di Fasilitas kesehatan cukup. Dari hasil uji statistik dengan menggunakan uji Chi Squarepada $\alpha=5 \%$ dan $\mathrm{df}=1$, diperoleh nilai $X^{2}$ hitung $<X^{2}$ tabel $(0,948>$ $3,841)$, artinya tidak ada hubungan yang bermakna Mini Lokakarya Puskesmas dengan cakupan program persalinan di fasilitas kesehatan di Kabupaten Konawe Selatan. Karena tidak terdapat hubungan maka tidak dilanjutkan dengan uji keeratan hubungan.

Tabel 1 Hubungan Mini Lokakarya Puskesmas dengan Cakupan Program Kunjungan Pelayanan Antenatal ke empat (K4)

\begin{tabular}{cccccccc}
\hline \multirow{2}{*}{$\begin{array}{c}\text { Mini } \\
\text { Lokakarya }\end{array}$} & \multicolumn{4}{c}{ Pelayanan Antenatal ke empat (K4) } & \multirow{2}{*}{$\mathrm{X}^{2}$} \\
\cline { 2 - 6 } & \multicolumn{2}{c}{ Kurang } & \multicolumn{2}{c}{ Cukup } & \multicolumn{2}{c}{ Jumlah } & Hitung \\
\cline { 2 - 6 } & $\mathrm{N}$ & $\%$ & $\mathrm{n}$ & $\%$ & $\mathrm{n}$ & $\%$ & \\
\hline Kurang & 18 & 66,7 & 9 & 33,3 & 27 & 100 & \\
\cline { 1 - 6 } Cukup & 29 & 50,0 & 29 & 50,0 & 58 & 100 & \\
\cline { 1 - 3 } & 47 & 55,3 & 38 & 44,7 & 85 & 100 & \\
\hline
\end{tabular}

Sumber :Data primer 2019 
Tabel 2 Hubungan Mini Lokakarya Puskesmas dengan Cakupan Program Persalinan oleh Tenaga Kesehatan (Pn)

\begin{tabular}{|c|c|c|c|c|c|c|c|}
\hline \multirow{3}{*}{$\begin{array}{c}\text { Mini } \\
\text { Lokakar } \\
\text { ya }\end{array}$} & \multicolumn{6}{|c|}{$\begin{array}{l}\text { Persalinan oleh Tenaga } \\
\text { Kesehatan }\end{array}$} & \multirow{2}{*}{$\begin{array}{c}\mathrm{X}^{2} \\
\text { Hitun } \\
\mathrm{g} \\
\end{array}$} \\
\hline & \multicolumn{2}{|c|}{ Kurang } & \multicolumn{2}{|c|}{ Cukup } & \multicolumn{2}{|c|}{ Jumlah } & \\
\hline & $\mathrm{N}$ & $\%$ & $\mathrm{n}$ & $\%$ & $\mathrm{n}$ & $\%$ & \multirow{7}{*}{0,948} \\
\hline \multirow{2}{*}{ Kurang } & 1 & 51 , & 1 & 48 , & 2 & 10 & \\
\hline & 4 & 9 & 3 & 1 & 7 & 0 & \\
\hline \multirow{2}{*}{ Cukup } & 2 & 37 , & 3 & 62 , & 5 & 10 & \\
\hline & 2 & 9 & 6 & 1 & 8 & 0 & \\
\hline \multirow{2}{*}{ Jumlah } & 3 & 42 , & 4 & 57 , & 8 & 10 & \\
\hline & 6 & 4 & 9 & 6 & 5 & 0 & \\
\hline
\end{tabular}

Sumber : Data primer 2019

Tabel 3 Hubungan Mini Lokakarya Puskesmas dengan Cakupan Program Persalinan di Fasilitas Kesehatan

\begin{tabular}{|c|c|c|c|c|c|c|c|}
\hline \multirow{3}{*}{$\begin{array}{c}\text { Mini } \\
\text { Lokakarya }\end{array}$} & \multicolumn{6}{|c|}{ Persalinan di Fasilitas Kesehatan } & \multirow{2}{*}{$\begin{array}{c}X^{2} \\
\text { Hitung }\end{array}$} \\
\hline & \multicolumn{2}{|c|}{ Kurang } & \multicolumn{2}{|c|}{ Cukup } & \multicolumn{2}{|c|}{ Jumlah } & \\
\hline & $\mathrm{n}$ & $\%$ & $\mathrm{n}$ & $\%$ & $\mathrm{n}$ & $\%$ & \multirow{4}{*}{0,948} \\
\hline Kurang & 14 & 51,9 & 13 & 48,1 & 27 & 100 & \\
\hline Cukup & 22 & 37,9 & 36 & 62,1 & 58 & 100 & \\
\hline Jumlah & 36 & 42,4 & 49 & 57,6 & 85 & 100 & \\
\hline
\end{tabular}

Sumber : Data primer 2019

Tabel 4 Hubungan Alokasi dana BOK dengan Cakupan Program Kunjungan Antenatal ke empat (K4)

\begin{tabular}{|c|c|c|c|c|c|c|c|c|}
\hline $\begin{array}{l}\text { Alokasi } \\
\text { Dana } \\
\text { BOK }\end{array}$ & \multicolumn{6}{|c|}{$\begin{array}{c}\text { Kunjungan Antenal ke empat } \\
\text { (K4) }\end{array}$} & \multirow[t]{3}{*}{$\begin{array}{c}X^{2} \\
\text { Hitung }\end{array}$} & \multirow[t]{3}{*}{$\operatorname{Phi}(\Phi)$} \\
\hline & \multicolumn{2}{|c|}{ Kurang } & \multicolumn{2}{|c|}{ Cukup } & \multicolumn{2}{|c|}{ Jumlah } & & \\
\hline & $\mathrm{n}$ & $\%$ & $\mathrm{n}$ & $\%$ & $\mathrm{n}$ & $\%$ & & \\
\hline Kurang & 36 & 72,0 & 14 & 2,80 & 50 & 100 & & \\
\hline Cukup & 11 & 31,4 & 24 & 68,6 & 35 & 100 & $12,11 /$ & 02 \\
\hline Jumlah & 47 & 55,3 & 38 & 44,7 & 85 & 100 & & \\
\hline
\end{tabular}

Sumber : Data primer 2019
Tabel 5 Hubungan Alokasi Dana BOK dengan Cakupan Program Persalinan oleh Tenaga Kesehatan (PN)

\begin{tabular}{ccccccccc}
\hline Alok & \multicolumn{4}{c}{ Persalinan oleh Tenaga } & & $\mathrm{X}^{2}$ & Phi \\
asi & \multicolumn{4}{c}{ Kesehatan (Pn) } & Hitu & $\Phi)$ \\
\cline { 2 - 6 } Dana & Kurang & Cukup & Jumlah & ng & \\
\cline { 2 - 7 } BOK & $\mathrm{n}$ & $\%$ & $\mathrm{n}$ & $\%$ & $\mathrm{n}$ & $\%$ & & \\
\hline Kura & 3 & 60, & 2 & 40, & 5 & 10 & & \\
ng & 0 & 0 & 0 & 0 & 0 & 0 & 13,7 & 0,42 \\
\hline Cuku & 6 & 17, & 2 & 82, & 3 & 10 & 83 & 7 \\
p & & 1 & 9 & 9 & 5 & 0 & & \\
\hline Juml & 3 & 42, & 4 & 5,7 & 8 & 10 & & \\
ah & 6 & 4 & 9 & 6 & 5 & 0 & & \\
\hline
\end{tabular}

Sumber : Data primer 2019

Tabel 6 Hubungan Alokasi Dana BOK dengan Cakupan Program Persalinan di Fasilitas Kesehatan

\begin{tabular}{|c|c|c|c|c|c|c|c|c|}
\hline \multirow{3}{*}{$\begin{array}{c}\text { Alokasi } \\
\text { Dana } \\
\text { BOK }\end{array}$} & \multicolumn{6}{|c|}{$\begin{array}{l}\text { Persalinan di Fasilitas Kesehatan } \\
\text { (Pf) }\end{array}$} & \multirow{3}{*}{$\begin{array}{c}X^{2} \\
\text { Hitung }\end{array}$} & \multirow[t]{3}{*}{$\operatorname{Phi}(\Phi)$} \\
\hline & \multicolumn{2}{|c|}{ Kurang } & \multicolumn{2}{|c|}{ Cukup } & \multicolumn{2}{|c|}{ Jumlah } & & \\
\hline & $\mathrm{n}$ & $\%$ & $\mathrm{n}$ & $\%$ & $\mathrm{n}$ & $\%$ & & \\
\hline Kuran & 30 & 60,0 & 20 & 40,0 & 50 & 100 & \multirow{3}{*}{13,783} & \multirow{3}{*}{0,427} \\
\hline Cukup & 6 & 17,1 & 29 & 82,9 & 35 & 100 & & \\
\hline Jumlah & 36 & 42,4 & 49 & 57,6 & 85 & 100 & & \\
\hline
\end{tabular}

Sumber : Data primer 2019

\section{PEMBAHASAN}

\section{Hubungan Mini Lokakarya dengan Cakupan Program Kesehatan Ibu}

Lokakarya Mini Puskesmas merupakan salah satu bentuk upaya penggalangan atau pemantauan berbagai kegiatan di puskesmas melalui pertemuan.(RI and KESEHATAN, 2004) Dalam pelaksanaan mini lokakarya di puskesmas dibagi dalam beberapa tahap yaitu lokakarya mini bulan pertama dan lokakarya mini bulanan rutin.(Sulistinah et al., 2017). Hasil penelitian yang dilakukan di 17 Puskesmas Kabupaten Konawe Selatan terhadap 85 responden, 58 responden menyakatan kegiatan mini lokakarya puskesmas terhadap keberhasilan program cakupan Kesehatan Ibu yakni pada pelayanan kesehatan antenatal ke 
empat (K4), Persalinan oleh Tenaga Kesehatan, Persalinan di Fasilitas Kesehatan adalah cukup. Hanya 27 responden menyatakan kurang.

Dari hasil uji statistik dengan menggunakan uji Chi Square diperoleh nilai signifikansi $0,955>$ nilai $\alpha=0,05$. Penelitian ini menunjukkan bahwa tidak ada hubungan yang bermakna antara mini lokakarya dengan cakupan program kesehatan Ibu di Kabupaten Konawe Selatan. Hal ini dikarenakan kegiatan mini lokakarya puskesmas sudah rutin dilaksanakan oleh puskesmas setiap bulan baik itu mini lokakarya lintas program maupun lokakarya lintas sector,(INDONESIA, 2016) namun dalam pelaksanaanya masih kurang efektif. 80 responden menyatakan Program Kesehatan Ibu menjadi salah satu agenda priotitas yang dibahas saat mini lokakarya tetapi pembahasan lebih cenderung kepada seberapa realisasi keuangan yang sudah di realisasikan setiap program, lebih focus pada pemeriksan penyelesaian administrasi atau pertanggung jawaban hasil pelaksanaan kegiatan yang di bersumber dana BOK.

Dari hasil penelitian diketahui bahwa terdapat 14 responden yang menyakatakan mini lokakarya kurang mempengaruhi capaian program persalinan di fasilitas kesehatan tetapi cakupan persalinan di fasilitas kesehatan cukup hal ini karenakan tuntutan bagi tenaga kesehatan (bidan) harus selalu ada dan siap di setiap fasilitas kesehatan untuk menangani persalinan atau dengan kata lain setiap persalinan harus ditangani oleh tenaga kesehatan), misalnya pada saat berlangsung kegiatan mini lokakarya di puskesmas, tenaga kesehatan (bidan) yang sedang menolong persalinan di polindes tidak di tuntut untuk hadir dalam kegiatan mini lokakarya.

Berdasarkan hasil penelitian diketahui bahwa tanpa adanya dana BOK di Puskesmas kegiatan Mini lokakrya Puskesmas tetap dilaksanan, baik itu lokakarya bulanan program maupun lokakarya lintas sektor, karena Mini lokakarya adalah kegiatan rutin yang wajib dilaksanakan oleh puskesmas.(INDONESIA， 2016) Tetapi dari hasil penelitian diketahui bahwa pelaksanaan mini lokakarya memang betul dilaksanakan namun hasilnya kurang efektif, karena tidak berdasarkan pada siklus manajemen puskesmas atau tidak sesuai standar operasional pelaksanaan mini lokakarya puskesmas. Rata-rata pelaksanaan mini lokakarya hanya 2 - 4 jam, dan dalam pelaksanaannya tidak membahas program kesehatan secara rinci, kegiatan program yang sudah dilaksanakan bulan lalu tidak dilakukan evaluasi secara detail, tidak melakukan analisa data, tidak mengidentifikasi masalah per program secara rinci, tidak mencari akar penyebab masalah, pemecaham masalah tidak berdasarkan pada prioritas masalah, lebih banyak membahas realisasi keuangan untuk setiap program dan hanya melihat secara umum pencapaian program tercapai atau tidak tercapai.

Berdasarkan siklus menejemen umum puskesmas dari segi perencanaan, penggerakan pelaksanaan, pengawasan pengendalian kinerja puskesmas, (Jenderal and Masyarakat, 2006) pelaksanaan mini lokakarya puskesmas belum sesuai yang diharapkan. Dari segi perencanaan, analisa situasi tidak dilakukan dengan baik melalui kegiatan analisis data, identifikasi masalah, prioritas masalah, akar masalah dan pemecahan masalah sehingga dalam penyusunan rencana usulan kegiatan tidak berdasarkan pada prioritas masalah.Dari segi penggerakan pelaksanaan mini lokakarya puskesmas dilaksanakan secara rutin bulanan dan tribulanan, dari segi pengawasan, pengendalian dan penilaian kinerja puskesmas seharunya setiap kegiatan program yang sudah dilaksanakan 
harus dilakukan evaluasi melalui penilaian kinerja puskesmas.(INDONESIA, 2016)

Peraturan Menteri Kesehatan Nomor 44 tahun 2016 tentang Pedoman Manajemen Puskesmas disebutkan bahwa pelaksanan mini lokakarya puskesmas harus berdasarkan siklus manajemen puskesmas dimana mini lokakarya bulanaan harus dilaksanakan setiap bulan, mini lokakarya lintas sector dilaksanakan sebanyak 4 (empat) kali dalam setahun yaitu pada bulan Februari, Mei, Agustus dan November. Pelaksanaan mini lokakarya harus dimulai dari Pembukaan, Dinamika kelompok (menumbuhkan motivasi), Pengenalan program baru, Inventarisasi kegiatan bulan lalu, Analisa Data, Indentifikasi masalah, menentukan prioritas masalah, mencari akar penyebab masalah dan bagaimana pemecahan masalah yang dilanjutkan dengan penyusunan kegiatan bulan yang akan datang atau POA Puskesmas. Faktor yang bisa menjadi salah satu penentu pencairan dana BOK adalah pengusulan POA sehingga Kepala Dinas Kesehatan disarankan untuk menjamin rutinitas sosialisasi dan pembinaan penyusunan POA Puskesmas demi efektif dan berjalan lancarnyanya kebijakan yang telah dibuat (Ainy, 2012), Pembagian tugas bulan yang akan datang, Kesepakatan untuk melaksanakan rencana kerja baru yang dilakukan setiap bulan dan teratur.

\section{Hubungan Alokasi Dana BOK dengan Cakupan Program Kesehatan Ibu}

Alokasi dana BOK per Puskesmas dimuat dalam Dana Alokasi Khusus (DAK) Non Fisik bidang kesehatan tahun anggaran 2018 yang dikeluarkan oleh Kementerian Kesehatan RI yang menyebutkan bahwa Alokasi Dana BOK per Puskesmas ditetapkan melalui SK Kepala Dinas Kesehatan Kabupaten atau Kota.(Laeliyah and Nadjib, 2017) Dana BOK yang telah diterima dapat digunakan oleh tenaga kesehatan yang menerima dana tersebut untuk melaksanakan kegiatan dan Upaya Kesehatan Masyarakat di setiap jenjang (primer, sekunder) serta dapat melakukan berbagai aktifitas yang mendukung manajemen kesehatan yang meliputi kegiatan-kegiatan di puskesmas yang dapat memberi manfaat bagi masyarakat (Wismantari et al., 2018).

Dana BOK dapat juga digunakan oleh pemerintah daerah guan mengalokasikan kegiatan untuk dukungan manajamen Organisasi Perangkat Daerah (OPD) Dinas Kesehatan Kabupaten dan Kota dan Puskesmas BLUD dengan besaran maksimal 5\% dari alokasi dana yang diterima,(Beratha et al., 2013) sebelum di distribusikan untuk masingmasing puskesmas. Pengalokasian dana diberikan berdasarkan sasaran programprogram kegiatan yang akan dilaksankaan. Alokasi Dana BOK per Puskesmas ditetapkan melalui Surat Keputusan Kepala Dinas Kesehatan Kabupaten/Kota.Dana BOK yang telah di alokasikan disetiap puskesmas dapat digunakan untuk pelaksanaan kegiatan upaya kesehatan masyakarat oleh puskesmas dan jaringannya (Aridewi et al., 2013)

Hasil analisis statistik dengan menggunakan uji Chi Squareuntuk melihat hubungan antara alokasi dana BOK dengan cakupan program kesehatan Ibu (Pelayanan antenatal ke empat, persalinan oleh tenaga kesehatan dan dilakukan di fasilitas kesehatan), diperoleh nilai $\mathrm{X}^{2}$ hitung $>\mathrm{X}^{2}$ tabel. Hasil ini menunjukkan bahwa ada hubungan yang bermakna dan sangat kuat antara alokasi dana BOK dengan cakupan program kesehatan Ibudiantaranya pelayanan kesehatan antenatal ke empat (K4), persalinan yang ditolong oleh tenaga kesehatan dan di lakukan di fasilitas kesehatan di Kabupaten Konawe Selatan. Berdasarkan hasil penelitian yang dilakukan terhadap 85 responden di 17 
Puskesmas Konawe Selatan diketahui bahwa sebanyak 50 responden menyatakan Alokasi Dana BOK terhadap Cakupan Program Kesehatan Ibu Kurang, dan hanya 14 responden menyatakan cukup.

Alokasi Dana yang didapatkan dari BOK yang diberikan ke Puskesmas setiap tahun meningkat atau bertambah namun tidak dibarengi dengan peningkatan capaian program kesehatan di puskesmas terutama program kesehatan Ibu(Hasan and Adisasmito, 2017a), berdasarkan hasil penelitian yang dilakukan terhadap 85 responden di puskesmas Kabupaten Konawe Selatan sebanyak 50 responden menyatakan pembagian alokasi dana BOK tidak melihat dari besaran masalah yang terjadi di masing-masing program, tidak dilakukan evaluasi progam terhadap kegiatan yang telah dilaksanakan sebelumnya, dalam menyusun Rencana Kegiatan Puskesmas tidak berdasarkan pada prioritas masalah yang terjadi. Ratarata alokasi dana BOK yang diberikan untuk pelayanan kesehatan Ibu di Kabupaten Konawe Selatan berkisar antara 5\% sampai dengan $20 \%$. Pembagian alokasi dana BOK juga tidak melihat dari luas wilayah kerja puskesmas, tidak melihat besaran sasaran Ibu hamil di setiap desa atau kelurahan, sehingga cakupan pelayanan kesehatan Ibu dalam hal ini pelayanan $\mathrm{K} 4$, persalinan oleh tenaga kesehatan dan persalinan di fasilitas kesehatan tidak pernah tercapai. Kisaran alokasi dana yang di berikan 5-10\% untuk program kesehatan Ibu sudah meliputi biaya transport lokal petugas kesehatan baik diluar gedung maupun dalam gedung,(Suharmiati et al., 2013) pembelian bahan habis pakai, biaya penyelenggaraan rapat-rapat, sosialisasi dan pertemuan koordinasi. Pemberian transportasi bagi petugas kesehatan sebagian besar diberikan hanya sampai pada kegiatan pelayanan di Posyandu saja, sehingga cakupan pelayanan kesehatan Ibu tidak akan pernah tercapai karena pelayanan kesehatan Ibu hamil hanya tercatat dan terlaporkan bagi Ibu hamil yang datang di Posyandu. Begitu pula dengan persalinan yang ditolong oleh tenaga kesehatan, dan persalinan di fasilitas kesehatan.

Pelayanan kesehatan bagi ibu khususnya ibu hamil sangat merasa terbantu dengan adanya dana BOK. Salah satu penggunaan dana BOK yang dapat digunakan oleh para tenaga kesehatan adalah kegiatan-kegiatan yang dilakukan diluar gedung yang memerlukan uang transport sehingga petugas kesehatan juga kan measa ada semangat dalam melakukan kegiatan tersebut. (Cahyadin, 2013). Dana BOK sejatinya yang berasal dari dana PBD pasti akan mengalami keterbatasan dalam penggunaan maupun pelaksaaan kegiatannya dikarenakan dana APBD setiap daerah pasti tidak sama oleh sebab itu tenaga kesehatan yang mengelola dana Bok diharapkan dapat memaksimalkan dan membuat perencaanaan proritas dalam penggunaan dana Bok khususnya dana yang digunakan di Puskesmas apalagi yang berkaitan dengan kesehatan ibu dan anak (Hasan and Adisasmito, 2017b)

Puskesmas dengan dana kapitasi besar memiliki keleluasaan lebih dalam pengelolaannya, sedangkan puskesmas dengan dana kapitasi kecil, sangat terbatas. Tahn 2014 merupakan awal pertama kali program JKN dilaksanakan di Indonesia dan sejak saat ada masih banyak masalah yang didpatkan akan tetapi pemerintah terus berupaya meningkatkan perbaikan dengan berbagai pihak guna menyukseskan program JKN tersebut. Banyak faktor yang menjadi permasalah JKN slah satu diantarany adalah rendahnya kualitas layanan kesehatan yang sangan dipengaruhi oleh biaya kesehatan (Hasan and Adisasmito, 2017b).

\section{KESIMPULAN}


Ada hubungan yang bermakna dan sangat kuat antara alokasi dana BOK dengan cakupan program kesehatan Ibu yakni Pelayanan Kesehatan Antenatal ke empat (K4), Persalinan di tolong oleh Tenaga Kesehatan dan Persalinan di Fasilitas Kesehatan di Kabupaten Konawe Selatan, dimana 50 responden menyatakan alokasi dana BOK untuk program kesehatan Ibu kurang karena dalam pembagian alokasi dana BOK tidak berdasarkan identifikasi masalah dan prioritas masalah. Untuk kegiatan Mini Lokakarya Puskesmas Tidak ada hubungan yang bermakna walaupun mini lokakarya sudah rutin di laksanakan tetapiinput proses dan output nya masih kurang efektif.

\section{DAFTAR PUSTAKA}

AINY, A. 2012. Pelaksanaan Kebijakan Bantuan Operasional Kesehatan di Kabupaten Ogan Ilir, Sumatera Selatan. Jurnal Kebijakan Kesehatan Indonesia, Volume 01, 7 - 12.

ARIDEWI, A., KARTASURYA, M. I. \& SRIATMI, A. 2013. Analisis pemanfaatan bantuan operasional kesehatan dalam upaya peningkatan kesehatan ibu dan anak di puskesmas wilayah kerja dinas kesehatan kabupaten Kudus. Jurnal Manajemen Kesehatan Indonesia, 1, 32-40.

BERATHA, O., WIRAKUSUMA, I. B. \& SUDIBYA, A. 2013. Hubungan karakteristik, motivasi dan dana BOK dengan kinerja petugas KIA Puskesmas di Kabupaten Gianyar, Udayana University.

CAHYADIN, U. P. S. M. 2013. Hubungan antara Realisasi Dana Bantuan Operasional Kesehatan Dengan Indikator Gizi KIA di Kabupaten/Kota Provinsi Jawa Tengah Tahun 2012. Jurnal Kebijakan Kesehatan Indonesia: JKKI, 2.
DINKES.KAB..KONSEL 2017. Profil Kesehatan Kabupaten Konawe Selatan Tahun 2017, Kendari, Dinas Kesehatan Kabupaten Konawe Selatan.

DINKES_PROV_SULTRA 2018. Profil Kesehatan Provinsi Sulawesi Tenggara Tahun 2017. Kendari: Dinas Kesehatan Prov. Sultra.

HASAN, A. G. \& ADISASMITO, W. B. 2017a. Analisis Kebijakan Pemanfaatan Dana Kapitasi JKN Pada FKTP Puskesmas Di Kabupaten Bogor Tahun 2016. Jurnal Kebijakan Kesehatan Indonesia: JKKI, 6, 127137.

HASAN, A. G. \& ADISASMITO, W. B. B. 2017b. Analisis Kebijakan Pemanfaatan Dana Kapitasi JKN pada FKTP Puskesmas di Kabupaten Bogor Tahun 2016. Jurnal Kebijakan Kesehatan Indonesia, 06, 10.

HUTAGALUNG, H. N. 2013. Analisis implementasi dan evaluasi efektifitas dana Bantuan Operasional Kesehatan (BOK) terhadap pencapaian Standar Pelayanan Minimal (SPM) bidang Kesehatan di Kota Sibolga Sumatera Utara.

INDONESIA, M. K. R. 2016. Peraturan Menteri Kesehatan Republik Indonesia Nomor 44 Tahun 2016 Tentang Pedoman Manajemen Puskesmas. Kementerian Kesehatan Republik Indonesia. Jakarta.

JAYADIPRAJA, E. A., PRASETYA, F., AZLIMIN, A. \& MANDO, W. O. S. Y. 2018. FAMILY CLEAN AND HEALTHY LIVING BEHAVIOR AND ITS DETERMINANT FACTORS IN THE VILLAGE OF LABUNIA, REGENCY OF MUNA, SOUTHEAST SULAWESI PROVINCE OF INDONESIA. Public Health of Indonesia, 4, 39-45. JENDERAL, I. D. K. R. D. \& MASYARAKAT, B. K. 2006. 
Pedoman lokakarya mini puskesmas[BUKU]. Jakarta: Departemen Kesehatan RI, 2006.

KEMENKES- 2015. Rencana Strategi Kementerian Kesehatan Tahun 2015 2019. In: R.I., K. K. (ed.). Jakarta.

KEMENKES 2011. Petunjuk Teknis Bantuan Operasional Kesehatan, Jakarta, Kemeterian Kesehatan R.I.

KEMENKES 2016. Peraturan Menteri Kesehatan Republik Indonesia Nomor 43 tentang Standar Pelayanan Minimal Bidang Kesehatan. Jakarta: Kementerian Kesehatan Republik Indonesia.

KEMENKES 2017. Peraturan Menteri Kesehatan Republik Indonesia Nomor 61 Tahun 2017 Tentang Petunjuk Teknis DAK Non Fisik Tahun Anggaran 2018. Jakarta: Kementerian Kesehatan R.I.

KEMENKES 2018. Profil Kesehatan Indonesia 2017. In: R.I., K. K. (ed.). Jakarta: Pusat Data dan Informasi Kementerian Kesehatan R.I.

KESEHATAN, P. T. B. O. 2013. PERATURAN MENTERI KESEHATAN REPUBLIK INDONESIA NOMOR 1 TAHUN 2014

LAELIYAH, S. N. \& NADJIB, M. 2017. Hubungan Pemanfaatan Dana Bantuan Operasional Kesehatan (BOK) dengan Peningkatan Cakupan Kunjungan Antenatal K4 di Puskesmas Kota Serang Tahun 2014-
2016. Jurnal Kebijakan Kesehatan Indonesia: JKKI, 6, 115-126.

RI, B. D. \& KESEHATAN, B. P. 2004. Manajemen Puskesmas. Jakarta: Departemen Kesehatan RI.

SAPUTRA, W., FANGGIDAE, V. \& MAFTHUCHAN, A. 2013. Efektivitas kebijakan daerah dalam penurunan angka kematian ibu dan bayi. Kesmas: National Public Health Journal, 7, 531-537.

SUHARMIATI, S., LAKSONO, A. D. \& ASTUTI, W. D. 2013. UP Review Kebijakan tentang Pelayanan Kesehatan Puskesmas di Daerah Terpencil Perbatasan. Buletin Penelitian Sistem Kesehatan, 16.

SULISTINAH, A., WITCAHYO, E. \& SANDRA, C. 2017. Kajian Kesiapan Dokumen Akreditasi Kelompok Kerja Administrasi Manajemen di Upt. Puskesmas Jelbuk Dinas Kesehatan Kabupaten Jember (Study of Preparation on Accreditation Document for Administration Management at Jelbuk Primary Health Center Jember). Pustaka Kesehatan, 5, 580-587.

WISMANTARI, M. W. J., SURYAWATI, C. \& ARSO, S. P. 2018. ANALISIS INPUT DAN LINGKUNGAN IBU MENYUSUI TERHADAP PROGRAM PEMBERIAN ASI EKSKLUSIF (Studi Kasus Puskesmas Pandanaran Kota Semarang). Jurnal Kesehatan Masyarakat (e-Journal), 6, 117-123. 